\title{
Práticas esportivas escolares na cidade de Santos-SP: o ponto de vista dos professores/treinadores
}

\author{
Carla Nascimento Luguetti ${ }^{1,2}$ \\ Luiz Tourinho Dantas ${ }^{1}$ \\ Myrian Nunomura ${ }^{1}$ \\ Maria Tereza Silveira Böhme ${ }^{1}$ \\ ${ }^{1}$ Escola de Educação Física e Esporte, Universidade de São Paulo, São Paulo, Brasil \\ ${ }^{2}$ Faculdade de Educação Física e Esporte, Universidade Santa Cecília, Santos, Brasil
}

\begin{abstract}
Resumo: $O$ objetivo do presente estudo foi analisar e caracterizar as condições das práticas esportivas escolares nas três redes de ensino no município de Santos, no ensino fundamental, com enfoque sobre: a) a formação acadêmica e experiência profissional dos professores/treinadores; b) a condição das instalações e dos materiais das escolas para as práticas esportivas. Através de questionários com questões abertas e fechadas, aplicados aos professores/treinadores $(n=85)$ de escolas estaduais, municipais e particulares, verificaram-se diferenças entre os professores/treinadores das três redes de ensino em relação à idade, experiência, formação e atualização; independente da origem da escola, a maioria é do sexo masculino e exerce outras atividades além das práticas esportivas escolares. As condições de uso e de manutenção das instalações e materiais das escolas públicas são piores dos que as descritas nas escolas privadas. Espera-se que os resultados contribuam para o melhor aproveitamento do potencial formativo das práticas esportivas na escola, e assim, estimulem e subsidiem futuras discussões sobre programas de iniciação esportiva neste contexto.
\end{abstract}

Palavras-chave: Esporte. Ensino. Recursos humanos.

\section{School sports in the city of Santos-SP: the point of view of teachers/coaches}

\begin{abstract}
The current research aims to analyze and characterize the conditions of the school sports in the elementary schools in the Municipality of Santos, focusing on: a) the academic and professional experience of teachers/coaches; b) the condition of facilities and equipment. By using questionnaires with open and closed questions for teachers/coaches $(n=85)$ in state, municipal and private schools, there were differences among teachers/coaches of the three school systems in relation to age, experience, training and updating. Regardless of the origin of the school, most professionals are male and carry out other activities beyond school sports. The conditions of use and maintenance of facilities and materials in public schools are worse than those described in private schools. It is hoped that the results contribute to a better utilization of the training potential of school sports, and thus encourage and promote future discussions about programs of sports initiation in this context.
\end{abstract}

Keywords: Sports. Teaching. Human Resources.

\section{Introdução}

No Ensino Fundamental, o esporte tem sido desenvolvido como um dos conteúdos da Educação Física Escolar. Porém, temos observado um crescimento no número de escolas brasileiras que também oferecem modalidades esportivas como atividades extracurriculares no contraturno, denominadas "práticas esportivas escolares (PEEs)", "esporte escolar" ou "turmas de treinamento" (BASSANI; TORRI; VAZ, 2003; LETTNIN, 2005; LUGUETTI, 2010; SANTOS; SIMÕES, 2007; SARTORI, 2005; SIGOLI, 2005; SOARES, 2003).

Como políticas públicas, no âmbito federal, existem dois programas voltados para a prática esportiva escolar: o "Segundo Tempo" e os
"Jogos Escolares Brasileiros". O programa "Segundo Tempo" é de competência da Secretaria de Esporte Educacional e os "Jogos Escolares Brasileiros" são eventos esportivos de responsabilidade da Secretaria de Esporte de Alto Rendimento. Desse modo, os programas que oferecem as PEEs no âmbito federal são geridos por diferentes secretarias do Ministério do Esporte, o que dificulta a elaboração de uma política única para o fomento dos mesmos. Talvez essa falta de articulação afete a qualidade dos programas, que podem ser vistos como ineficientes, pois, ou não abrangem número significativo de crianças, como o "Segundo Tempo", ou são eventos pontuais, como os "Jogos Escolares". Ressaltamos que essa falta de integração é comum na esfera federal, em que 
poucos programas articulam diferentes setores do governo e incentivam a participação da sociedade civil (PACHECO, 2009).

O governo do Estado de São Paulo organiza a "Olimpíada Colegial do Estado de São Paulo", que é um evento realizado numa parceria entre a Secretaria de Educação e a Secretaria de Esporte, Lazer e Turismo. Com o objetivo de se prepararem para a participação nas Olimpíadas Colegiais, as escolas da rede estadual de São Paulo podem oferecer aos alunos um programa de treinamento, conhecido como "Atividades Curriculares Desportivas" (ACDs) ou turmas de treinamento. Infelizmente, os resultados de pesquisas realizadas em escolas estaduais revelam uma prática seletiva que visa ao alcance de resultados nas Olimpíadas Colegiais do Estado de São Paulo (LUGUETTI, 2010; SANTOS; SIMÕES, 2007; SOARES, 2003), o que de certa forma revela uma inadequação dessas atividades para o currículo.

No município de Santos-SP, as escolas municipais desenvolvem um programa denominado "Escola Total", cujo objetivo é ampliar o tempo de permanência dos alunos das unidades municipais de ensino em atividades educativas nas áreas de cultura, artes e esportes. Para oferecer estas atividades, a prefeitura de Santos-SP utiliza espaços disponibilizados por clubes, espaços privados sem fins lucrativos, escolas estaduais, entidades de bairros, sindicatos e escolas novas construídas com espaço para oferecer as atividades. Sartori (2003) e Luguetti (2010) avaliaram o objetivo das PEEs em escolas que aplicavam o programa "Segundo Tempo", e verificaram uma preocupação dos gestores com a formação integral dos alunos. No entanto, Bassani et al. (2003) verificaram resultados diferentes numa escola municipal em que os alunos participavam de competições e as PEEs seguiam o modelo do alto rendimento. De acordo com Lettnin (2005), Luguetti (2010) e Sigoli (2005), as PEEs desenvolvidas em escolas privadas podem fazer parte de uma estratégia de marketing e, muitas vezes, não têm qualquer relação com o projeto político pedagógico da escola e, consequentemente, com a formação de crianças e de jovens.

Apesar do potencial das PEEs para a educação de crianças e de jovens, investigações apontam problemas nos programas oferecidos. Para que as PEEs possam auxiliar na formação integral de crianças e jovens seria necessária a atuação de um professor/treinador capacitado (MARCON et al., 2010; MOLINA; MOLINA NETO, 2001; NELSON et al., 2006; TOKUYOCHI et al., 2008; TRUDEL; GILBERT, 2006). Para a Unesco (2004), Libâneo (2004) e Gadotti (2000), o desafio da educação é preparar o professor que seja capaz de educar as crianças e os jovens no momento atual, que forme cidadãos capazes de construir alternativas e saídas para desafios que Ihes são colocados no cotidiano. Nesse contexto, - papel do professor, sua formação, sua experiência e suas impressões sobre a escola, constituem tema de debates necessários na educação. Muitos desses debates têm impacto sobre as políticas públicas para a educação e, com frequência, apresentam as várias dificuldades que caracterizam a realidade vivida pela maioria dos professores e das escolas do país (UNESCO, 2004).

Apesar de ter havido muita atenção sobre as pesquisas que avaliam os programas de PEEs (BASSANI; TORRI; VAZ, 2003; LETTNIN, 2005; SANTOS; SIMÕES, 2007; SARTORI, 2005; SIGOLI, 2005; SOARES, 2003), consideravelmente menos estudos foram realizados sobre 0 professor/treinador que atua nesses programas. Diante desse fato, o objetivo do presente estudo foi analisar e caracterizar as condições das práticas esportivas escolares das três redes de ensino fundamental no município de Santos-SP, considerando a formação acadêmica e experiência profissional dos professores/treinadores e a condição das instalações e dos materiais das escolas para as práticas esportivas. Em outras palavras, pretendemos conhecer quem são os professores responsáveis pelas PEEs e, através destes, levantar as condições em que são desenvolvidas as PEEs. Com base nessas informações esperase identificar o potencial formativo desses programas e sua relação com a escola.

\section{Materiais e Métodos}

Foi realizada uma pesquisa do tipo descritivo (survey), cujo objetivo é estudar o status de um fenômeno (THOMAS; NELSON, 2002).

O levantamento da população a ser estudada foi feito mediante o contato com a Diretoria de Ensino de Santos-SP, a qual forneceu o nome das escolas e dos respectivos diretores responsáveis. O município de Santos possui um total de 147 escolas do ensino fundamental. Por 
meio de contato telefônico, verificou-se que 123 destas instituições ofereciam PEEs, o que corresponde a $85 \%$ do total de escolas do município (74 escolas privadas, 37 escolas municipais e 12 escolas estaduais).

A amostra foi composta por 49 professores da rede privada, 26 da rede municipal e 10 da rede estadual. Com relação ao número de escolas, foi incluída a totalidade de escolas estaduais e municipais que ofereciam as PEEs (municipais $n=35$ e estaduais $n=12$ ); em relação às escolas privadas selecionou-se por amostragem estratificada aleatória 12 escolas, levando-se em consideração as regiões (bairros) do município de Santos.

Como instrumento de medida, foi utilizado um questionário elaborado segundo a técnica sugerida por Thomas e Nelson (2002) e baseado nos estudos de Arena (2000), Lettnin (2005), Tsukamoto (2004) e Unesco (2004). A validade de conteúdo do instrumento utilizado foi obtida através do julgamento de especialistas (SAFRIT, 1981), sendo três professores da Escola de Educação Física e Esporte da Universidade de São Paulo. A validação do instrumento se deu sob os aspectos de clareza e objetividade de linguagem e relação com os objetivos do estudo. Cada professor especialista recebeu uma síntese do projeto com os objetivos e o instrumento (questionário direcionado aos professores/treinadores). Como critérios de inclusão, os especialistas deveriam apresentar título de doutorado e experiência na área de Pedagogia do Esporte. Os especialistas apresentaram média de 15 anos de experiência no Ensino Superior e média de cinco anos de experiência na área de prática de ensino e de treinamento esportivo na escola. $O$ instrumento foi testado num estudo piloto e algumas questões foram readequadas (LUGUETTI, 2010). O questionário foi dividido em duas partes: a) a formação acadêmica e a experiência profissional dos professores/treinadores; b) a condição das instalações e dos materiais das escolas para as práticas esportivas.

Os questionários foram entregues nas escolas, acompanhados de uma carta de esclarecimento com a explicação e propósito do estudo e o termo de consentimento livre e esclarecido. Responderam ao questionário 85 professores/treinadores, sendo 49 de escolas privadas, 26 de escolas municipais e 10 de escolas estaduais. Considerou-se apenas um professor/treinador por escola, de tal forma que a amostra correspondeu a $66,2 \%$ dos professores/treinadores de escolas privadas, $70,2 \%$ dos professores/treinadores das escolas municipais e $83,3 \%$ dos professores/treinadores de escolas estaduais.

Todos os professores/treinadores avaliados assinaram 0 termo de consentimento livre e esclarecido. O presente estudo foi apreciado e aprovado pelo Comitê de Ética da Escola de Educação Física e Esporte da Universidade de São Paulo (CEP: 2010/08).

Para a análise dos dados foram considerados três grupos respectivamente: redes de ensino estadual, municipal e privada. As variáveis foram classificadas em quantitativas e qualitativas. Para as variáveis quantitativas, foram realizados os testes de normalidade e de homocedasticidade, em que apenas a idade de início do treinamento e a de início na competição apresentaram distribuição normal; foi realizada a Análise de Variância a um fator para verificar as possíveis diferenças entre as redes de ensino. Como as demais variáveis não apresentaram distribuição normal, utilizou-se a estatística não paramétrica, através do emprego de mediana e amplitude, e do teste de Kruskal Wallis, para verificar a existência de diferenças estatisticamente significantes entre os grupos considerados.

Foram elaboradas tabelas cruzadas da frequência de distribuição das variáveis qualitativas, considerando-se as três redes de ensino; foi calculado o teste Qui-quadrado para verificar a existência de diferenças significantes entre os grupos estudados. Adotou-se o nível de significância de 5\% na interpretação das análises estatísticas realizadas. Foi utilizado o programa SPSS 13.0 for Windows para análise dos dados.

\section{Resultados e Discussão}

Os resultados e a discussão serão apresentados de acordo com as categorias em que foram divididas as questões do instrumento: a) a formação acadêmica e a experiência profissional dos professores/treinadores; b) a condição das instalações e dos materiais das escolas para as práticas esportivas.

\section{Formação acadêmica e experiência profissional \\ Quanto à idade do professor, no total, a mediana (Me) de idade foi de 31,65 anos.}


Verificou-se diferença estatisticamente significante (Kruskal Wallis $=36,7 ; p=0,000$ ) entre os grupos: os professores da rede estadual são mais velhos $(\mathrm{Me}=46)$, seguidos dos professores da rede privada $(\mathrm{Me}=31)$ e municipal $(\mathrm{Me}=22)$. $\mathrm{A}$ maioria dos professores é do sexo masculino $(63,5 \%)$, independentemente da origem da escola.

O tempo de experiência dos professores com PEEs é estatisticamente diferente entre as três redes de ensino pesquisadas. Os professores da rede privada trabalham há mais tempo (46 meses), seguido daqueles da rede estadual, com 30 meses, e da rede municipal, com seis meses (teste de Kruskal Wallis=36,4; $p=0,000$ ).

O fato da maioria dos professores/profissionais do município ser mais jovem e menos experiente pode ser atribuído a uma característica do programa, com relação à seleção dos seus profissionais. O programa desenvolvido no âmbito municipal trabalha com estagiários/monitores (graduandos de Educação Física), supervisionados por profissionais (nas áreas de Educação Física, Esporte, Pedagogia, Administração, entre outras).

Os professores/treinadores das escolas privadas e municipais são relativamente jovens, se comparados com professores de Ensino Fundamental de todo o Brasil (UNESCO, 2004), onde se verificou média de idade de 37,8 anos; e com professores apenas do Estado de São Paulo (TOKUYOCHI et al., 2008), onde a maior frequência etária ocorreu entre 30 e 50 anos de idade.

O tempo de experiência dos professores/treinadores da rede estadual foi inferior ao encontrado no estudo de Tokuyochi et al. (2008), em que $61 \%$ da amostra apresentou experiência acima de 10 anos (professores de Educação Física do Estado de São Paulo). No presente estudo, a experiência apresentada pelos professores/treinadores das escolas estaduais foi inferior a quatro anos (46 meses). $O$ fato do tempo de experiência no nosso estudo ser inferior ao de outros estudos realizados com professores de diferentes disciplinas no ensino fundamental e na Educação Física Escolar demonstra que os professores/treinadores de PEEs têm pouca experiência. A pouca experiência com PEEs apresentada pelos professores do Estado pode ser explicada pela resolução da abertura das turmas de treinamento no Estado, que entrou em vigor em 5-12-2002, ou seja, a abertura das turmas de treinamento só pôde ocorrer após esta data.

A experiência como professor/treinador é descrita por Marcon et al. (2010) e Nelson et al. (2006) como importante indicativo de conhecimentos. Para os autores, a formação de um professor/treinador é uma complexa combinação de aprendizagem formal (que ocorre num sistema institucionalizado), não formal (qualquer atividade sistemática organizada fora do sistema formal, como seminários, workshops e clínicas) e informal (o longo processo longo pelo qual cada pessoa adquire e acumula conhecimentos, habilidades, atitudes e percepções das experiências diárias e exposição ao ambiente). A experiência como professor/treinador é condição necessária para aquisição de conhecimento profissional de natureza tácita, aquele conhecimento que está associado à capacidade de executar os planos de aula. Ressaltamos que existem outras experiências necessárias para ser professor, entre as quais se destaca o conhecimento específico das modalidades esportivas.

Observou-se que os professores/treinadores são, em sua maioria, do sexo masculino, independentemente da origem da escola. Estudo da Unesco (2004) avaliou professores de Ensino Fundamental de todo o Brasil e concluiu que $81,3 \%$ são mulheres e $18,6 \%$ são homens. Unesco (2004) cita que no ensino fundamental existe uma feminilização da docência. De acordo com a pesquisa, o conceito de feminilização não se refere apenas à participação maciça de mulheres nos quadros docentes, mas, também, à adequação do magistério às características associadas tradicionalmente ao sexo feminino, como o cuidado. De acordo com os autores, no ensino fundamental há mais mulheres atuantes e, no ensino médio, algumas disciplinas como a matemática têm maioria de homens. O maior número de homens responsáveis pelas PEEs pode ser visto como uma consequência positiva da presença de programas esportivos nas escolas. As crianças necessitam de modelos adultos na fase de formação e, geralmente, as mulheres (as mães) são aquelas que passam a maior parte do tempo com elas. O convívio com 
ambos, homem e mulher, pode contribuir para compreender papéis sociais, desenvolver autoconfiança, entre outros (NUNOMURA et al., 2009).

Tabela 1. Frequência absoluta (FA), frequência relativa (FR) e resultado do teste de Qui-quadrado para a variável: "professor/treinador ter sido atleta da modalidade que ministra"

\begin{tabular}{c|c|c|c|c|c}
\hline \multicolumn{2}{c}{} & \multicolumn{5}{c}{ ORIGEM DAS ESCOLAS $^{\mathrm{a}}$} & \multirow{2}{*}{ Total } \\
\cline { 3 - 6 } \multirow{2}{*}{ não } & FA & 16 & 18 & 7 & 41 \\
& FR & $33,3 \%$ & $69,02 \%$ & $77,8 \%$ & $49,4 \%$ \\
\hline \multirow{2}{*}{ sim } & FA & 32 & 8 & 2 & 42 \\
& FR & $66.7 \%$ & $30,8 \%$ & $22,2 \%$ & $50,6 \%$ \\
\hline \multirow{2}{*}{ Total } & FA & 48 & 26 & 9 & 83 \\
& FR & $100,0 \%$ & $100,0 \%$ & $100,0 \%$ & $100,0 \%$ \\
\hline
\end{tabular}

a. Qui-quadrado $=11,9 ; p=0,003$

A maioria dos professores da rede privada foi atleta da modalidade que ministra, o que não foi verificado entre aqueles da rede estadual e municipal (Tabela 1). $\bigcirc$ percentual de professores/treinadores com experiência de atleta foi significativamente diferente entre os grupos analisados.

O maior percentual de professore/treinadores ex-atletas nas escolas privadas pode ser explicado pelo fato de que a maioria dos entrevistados destas instituições está envolvida com torneios competitivos da cidade de Santos. A cobrança por resultados faz com que os gestores das escolas privadas prefiram professores que obtiveram conquistas nas modalidades que ministram, apoiados na falsa ideia de que atletas medalhistas formariam atletas medalhistas. É comum encontrarmos técnicos que foram atletas de alto nível e que reproduzem condutas, comportamentos e métodos de treinamento de sua experiência anterior, mesmo que estas sejam questionáveis ou duvidosas e não encontrem apoio científico.

Os professores das escolas estaduais também são cobrados por resultados na Olimpíada Colegial do Estado de São Paulo. Entretanto, conforme a resolução 173 de 5-12-2002, as PEEs
As demais variáveis relativas à caracterização, experiência e formação acadêmica são apresentadas nas Tabelas 1 a 5 .

Tabela 2. Frequência absoluta (FA), frequência relativa (FR) e resultado do teste de Qui-quadrado para a variável: "outras atividades exercidas pelos professores/treinadores"

\begin{tabular}{|c|c|c|c|c|c|}
\hline & & \multicolumn{3}{|c|}{ ORIGEM DAS ESCOLAS ${ }^{a}$} & \multirow[b]{2}{*}{ Total } \\
\hline & & PRIVADAS & MUNICIPAIS & ESTADUAIS & \\
\hline $\operatorname{sim}$ & $\begin{array}{l}\text { FA } \\
\text { FR }\end{array}$ & $\begin{array}{c}39 \\
81,3 \%\end{array}$ & $\begin{array}{c}17 \\
65,4 \%\end{array}$ & $\begin{array}{c}4 \\
40,0 \%\end{array}$ & $\begin{array}{c}60 \\
71,4 \%\end{array}$ \\
\hline não & $\begin{array}{l}\text { FA } \\
\text { FR }\end{array}$ & $\begin{array}{c}9 \\
18,8 \% \\
\end{array}$ & $\begin{array}{c}9 \\
34,6 \% \\
\end{array}$ & $\begin{array}{c}6 \\
60,0 \% \\
\end{array}$ & $\begin{array}{c}24 \\
28,6 \% \\
\end{array}$ \\
\hline Total & $\begin{array}{l}\text { FA } \\
\text { FR }\end{array}$ & $\begin{array}{c}48 \\
100,0 \% \\
\end{array}$ & $\begin{array}{c}26 \\
100,0 \% \\
\end{array}$ & $\begin{array}{c}10 \\
100,0 \% \\
\end{array}$ & $\begin{array}{c}84 \\
100,0 \% \\
\end{array}$ \\
\hline
\end{tabular}

a. Qui-quadrado= 7,574; $p=0,023$

são propostas pelos professores à Diretoria de Ensino para a devida homologação e, a seguir, estas aulas são atribuídas. Assim, os professores/treinadores nem sempre são deslocados para as turmas de treinamento que idealizaram ou que desejam.

A experiência como atleta da modalidade é relatada como importante para os professores/treinadores. Lettnin (2005) avaliou professores e observou que os mesmos relataram que a graduação foi insuficiente para a atuação profissional, e que a experiência (vivência prática) na modalidade ajudaria a ministrá-la. A experiência como ex-atleta pode facilitar 0 caminho para se tornar um treinador, pois se está familiarizado com o ambiente, com os papéis e regras. Para os autores, em modalidades como o judô, os treinadores são qualificados por um sistema diferente, que exige experiência de alto nível como um atleta. Trudel e Gilbert (2006) avaliaram treinadores de alto rendimento e observaram que a maior parte é ex-atleta da modalidade. Possivelmente, a vivência prática nas modalidades esportivas, associada ao conhecimento teórico pode auxiliar na prática pedagógica do professor/treinador. 
A maioria dos professores/treinadores das escolas privadas e municipais exerce outras atividades além das PEEs (Tabela 2), o que não acontece na rede estadual. Os professores/treinadores das escolas municipais são graduandos e, portanto, ainda frequentam um curso superior. Com relação às outras atividades profissionais destacam-se a Educação Física Escolar e o trabalho em clubes e centros de treinamento, não se observando diferença estatisticamente significante entre as três redes de ensino. De acordo com a Unesco (2004), o tipo de vínculo do professor determina se ele exercerá outra atividade remunerada. Os autores citam que, no ensino público brasileiro, são os professores com contratos regidos pela CLT aqueles que mais se dedicam a outra atividade remunerada $(16,5 \%)$, seguidos pelos docentes com contratos temporários (14,9\%) e pelos efetivos sem concurso (12,6\%); dos professores efetivos concursados, $11,8 \%$ declararam que exercem outra atividade remunerada. Diante disso, existe uma grande preocupação com a terceirização do profissional que atua com as PEEs.

A instituição precisa preocupar-se com o envolvimento desse profissional com 0 projeto político pedagógico e com uma política de formação continuada. Segundo Lettnin (2005), o professor contratado pode ocasionar a falta de identificação com a escola; geralmente, aqueles que possuem carteira assinada encontram-se presentes em todas as atividades da escola; sobre aqueles que possuem um contrato de prestação de serviços, estes parecem estar desconectados do contexto comum.

Nesse sentido, o professor/treinador que atua mais tempo na escola pode conhecer melhor o projeto político pedagógico da instituição, e facilitar políticas de capacitação/formação continuada. $O$ professor/treinador deveria, preferencialmente, cumprir sua jornada de trabalho em uma única escola, talvez desenvolvendo aulas de educação física e PEEs. $\mathrm{E}$, ao permanecer no mesmo local de trabalho, a possibilidade de seu envolvimento com os projetos da escola é maior.

Em pesquisa realizada com professores de todo território nacional, com o objetivo de analisar as mudanças que poderiam ocorrer no trabalho docente, verificou-se que os professores desejavam aumentar o tempo e as possibilidades de trabalho em equipe com outros colegas, tanto em sala de aula como fora dela $(87,6 \%)$ e favorecer a concentração da carga horária dos docentes em apenas um estabelecimento $(86,7 \%)$ (UNESCO, 2004).

Tabela 3. Frequência absoluta (FA), frequência relativa (FR) e resultado do teste de Qui-quadrado para a variável "formação profissional dos professores/treinadores em Educação Física"

\begin{tabular}{c|c|c|c|c|c}
\hline \multicolumn{2}{c}{} & \multicolumn{5}{c}{ ORIGEM DAS ESCOLAS $^{\mathrm{a}}$} & \multirow{2}{*}{ Total } \\
\cline { 3 - 5 } Graduado em Educação & FA & 0 & 25 & 0 & 25 \\
física & FR & $0 \%$ & $95,2 \%$ & $0 \%$ & $29,8 \%$ \\
\hline \multirow{2}{*}{ Bacharel e licenciado } & FA & 27 & 1 & 1 & 29 \\
& FR & $56,3 \%$ & $3,8 \%$ & $10,0 \%$ & $34,5 \%$ \\
\hline Bacharel & FA & 0 & 0 & 1 & 1 \\
& FR & $0 \%$ & $0 \%$ & $10,0 \%$ & $1,2 \%$ \\
\hline Licenciado & FA & 3 & 0 & 8 & 25 \\
& FR & $6,3 \%$ & $0 \%$ & $80,0 \%$ & $31,0 \%$ \\
\hline Não possui habilitação em & FA & 3 & 0 & 0 & 3 \\
Educação Física & FR & $6,3 \%$ & $0 \%$ & $0 \%$ & $3,5 \%$ \\
\hline Total & FA & 48 & 26 & 10 & 84 \\
& FR & $100,0 \%$ & $100,0 \%$ & $100,0 \%$ & $100,0 \%$ \\
\hline
\end{tabular}

a. Qui-quadrado $=92,2 ; p=0,000$

Verificou-se a existência de diferença estatisticamente significante na formação docente dos profissionais das redes de ensino privada, estadual e municipal (Tabela 3). A maior parte dos professores/treinadores da rede estadual possui apenas o diploma de licenciado pelo fato de terem mais idade e serem formados numa época em que existiam apenas o curso de licenciatura. O mesmo não ocorre na rede privada, onde a maioria dos profissionais possui dupla titulação, ou seja, são bacharéis e licenciados. $\mathrm{Na}$ rede municipal, quase que a totalidade dos professores de PEEs é graduando em Educação Física, devido ao convênio existente entre a Secretaria Municipal de Educação e o programa Segundo Tempo do governo federal. 
Tabela 4. Frequência absoluta (FA), frequência relativa (FR) e resultado do teste de Qui-quadrado para a variável "cursos de atualização dos professores/treinadores"

\begin{tabular}{|c|c|c|c|c|c|}
\hline & & \multicolumn{3}{|c|}{ ORIGEM DAS ESCOLAS ${ }^{a}$} & \multirow[b]{2}{*}{ Total } \\
\hline & & PRIVADAS & MUNICIPAIS & ESTADUAIS & \\
\hline Não & $\begin{array}{l}\text { FA } \\
\text { FR }\end{array}$ & $\begin{array}{c}15 \\
31,3 \%\end{array}$ & $\begin{array}{c}21 \\
80,8 \%\end{array}$ & $\begin{array}{c}3 \\
33,3 \%\end{array}$ & $\begin{array}{c}39 \\
47,0 \%\end{array}$ \\
\hline $\operatorname{sim}$ & $\begin{array}{l}\text { FA } \\
\text { FR }\end{array}$ & $\begin{array}{c}33 \\
68,8 \%\end{array}$ & $\begin{array}{c}5 \\
19,2 \%\end{array}$ & $\begin{array}{c}6 \\
66,7 \%\end{array}$ & $\begin{array}{c}44 \\
53,0 \%\end{array}$ \\
\hline Total & $\begin{array}{l}\text { FA } \\
\text { FR }\end{array}$ & $\begin{array}{c}48 \\
100,0 \%\end{array}$ & $\begin{array}{c}26 \\
100,0 \%\end{array}$ & $\begin{array}{c}9 \\
100,0 \%\end{array}$ & $\begin{array}{c}83 \\
100,0 \%\end{array}$ \\
\hline
\end{tabular}

a. Qui-quadrado $=17,3 ; p=0,000$

Observou-se que a maioria dos professores de escolas privadas e estaduais realiza cursos de atualização (Tabela 4). Na rede municipal, um percentual pequeno dos graduandos realizou alguma capacitação além da graduação que está cursando.

O percentual de professores formados nas escolas privadas e estaduais foi maior do que os valores encontrados entre professores do ensino fundamental de todo o Brasil pela Unesco (2004), que registrou que apenas $60,3 \%$ dos professores possuem nível superior, e $29 \%$ nível médio, com formação pedagógica (ensino normal). Os professores das escolas municipais são graduandos de cursos de Educação Física da cidade de Santos que oferecem dupla graduação (licenciatura e bacharelado). Ressaltamos que a maioria dos cursos de Educação Física da Baixada Santista é oferecido nesse formato.

Os professores/treinadores das escolas privadas e estaduais possuem mais cursos de atualização. Destacamos que os cursos formais de especialização não são as únicas modalidades de educação continuada desses professores/treinadores, que participam de cursos, congressos, seminários de estudo, estudos individuais, reuniões pedagógicas, dentre outros. Para Libâneo (2004), a formação inicial tem um papel muito importante na capacitação do professor, mas a educação continuada permite que os profissionais se tornem mais qualificados. O autor cita que a educação continuada deve ocorrer de forma reflexiva, preferencialmente nas escolas onde trabalham, instigando-o a desenvolver autonomia profissional, a questionar e refletir sobre a sua prática e analisá-la à luz da teoria. Essa é uma das limitações desse estudo, pois o questionário não permitiu a captação dessas outras modalidades de educação continuada. No entanto, as modalidades de educação continuada formais não deixam de ser um indicador da atitude do profissional em busca de aprimoramento, como também, do apoio da instituição em relação ao desenvolvimento do seu profissional.

Lettnin (2005) avaliou escolas privadas e observou que apenas $22 \%$ delas oferecem incentivo financeiro para a qualificação profissional. A autora cita que a qualificação existe por interesse dos professores, que não querem perder seus empregos e por isso buscam, através de novos conhecimentos, possibilidades de melhorar sua atuação pedagógica no ambiente escolar. Para a Unesco (2004), a educação continuada deve ocorrer preferencialmente nas escolas em que o professor trabalha, pois a busca isolada pela atualização é mais difícil e o local de trabalho é o espaço ideal para este tipo de formação. De acordo com os pesquisadores, quando questionaram professores sobre a possibilidade de acrescentar mais dez horas de trabalho remunerado por semana na escola em que atuam, e quais atividades eles escolheriam para desenvolver nesse período, 0 auto aperfeiçoamento (ler, buscar novos materiais) e a educação continuada foram as mais citadas. $O$ fato revelou a necessidade que os docentes têm de investimento na sua formação, face às novas exigências da educação. Destaca-se que a maioria declarou que gostaria de participar de educação continuada se existisse um estímulo, como aumento salarial ou incentivo ao plano de carreira.

Entre as escolas avaliadas, apenas as municipais realizam reuniões pedagógicas semanais para a formação dos profissionais, onde discutem o programa de esporte realizado nas escolas. Para Libâneo (2004), as reuniões pedagógicas devem transformar o professor num 
pesquisador, enriquecendo-o de conhecimentos e práticas que o permitam resolver problemas, inclusive, os imprevistos.

Molina e Molina Neto (2001) avaliaram a capacitação dos professores de Educação Física Escolar da rede municipal de ensino da cidade de Porto Alegre/RS. A avaliação propunha fazer uma reflexão sobre a especificidade da disciplina e sua contribuição para o projeto pedagógico da "Escola Cidadã" (proposta daquele município). $\mathrm{O}$ programa de capacitação oferecia aos participantes a oportunidade de discutir sua ação docente e os instrumentos teórico-metodológicos. A maioria dos professores/treinadores avaliados afirmou que o conhecimento técnico da Educação Física não respondia satisfatoriamente aos problemas práticos de suas aulas; segundo os mesmos, o programa possibilitou novos procedimentos e estratégias didáticas inovadoras. Assim, a formação continuada de professores/treinadores deve ocorrer preferencialmente na própria instituição (escola), de maneira que sejam discutidos os problemas práticos enfrentados pelos docentes.

A perspectiva de crescimento na carreira de um treinador exige mais do que um programa de graduação pode oferecer. Além de um programa de formação continuada oferecido pela escola, deveria existir uma articulação entre as instituições responsáveis (por exemplo: confederações, federações ou ligas) que se responsabilizassem por qualificar e certificar os treinadores/professores. Tal articulação ocorre em países como o Canadá, e em poucas modalidades no Brasil. Contudo, no Esporte Escolar, provavelmente essas iniciativas não ocorrem, pois a preocupação principal é a organização dos eventos esportivos.

\section{Condição das instalações e dos materiais das escolas}

A opinião dos professores/treinadores sobre os recursos materiais e financeiros estão descritos nas Tabelas 5 e 6.

Tabela 5. Frequência absoluta (FA), frequência relativa (FR) e resultado do teste de Qui-quadrado para a variável "opinião dos professores/treinadores quanto às condições de uso das instalações"

\begin{tabular}{|c|c|c|c|c|c|}
\hline & & \multicolumn{3}{|c|}{ ORIGEM DAS ESCOLAS ${ }^{a}$} & \multirow[b]{2}{*}{ Total } \\
\hline & & PRIVADAS & MUNICIPAIS & ESTADUAIS & \\
\hline Precário & $\begin{array}{l}\text { FA } \\
\text { FR }\end{array}$ & $\begin{array}{c}0 \\
0 \% \\
\end{array}$ & $\begin{array}{c}26 \\
26,9 \% \\
\end{array}$ & $\begin{array}{c}2 \\
22,2 \% \\
\end{array}$ & $\begin{array}{c}9 \\
12,7 \% \\
\end{array}$ \\
\hline Satisfatório & $\begin{array}{l}\text { FA } \\
\text { FR }\end{array}$ & $\begin{array}{c}12 \\
33,3 \% \\
\end{array}$ & $\begin{array}{c}14 \\
53,8 \% \\
\end{array}$ & $\begin{array}{c}3 \\
33,3 \% \\
\end{array}$ & $\begin{array}{c}29 \\
40,8 \% \\
\end{array}$ \\
\hline Bom & $\begin{array}{l}\text { FA } \\
\text { FR }\end{array}$ & $\begin{array}{c}17 \\
47,2 \% \\
\end{array}$ & $\begin{array}{c}4 \\
15,4 \% \\
\end{array}$ & $\begin{array}{c}3 \\
33,3 \% \\
\end{array}$ & $\begin{array}{c}24 \\
33,8 \% \\
\end{array}$ \\
\hline Ótimo & $\begin{array}{l}\text { FA } \\
\text { FR }\end{array}$ & $\begin{array}{c}7 \\
19,4 \%\end{array}$ & $\begin{array}{c}1 \\
3,8 \%\end{array}$ & $\begin{array}{c}1 \\
11,1 \%\end{array}$ & $\begin{array}{c}9 \\
12,7 \% \\
\end{array}$ \\
\hline Total & $\begin{array}{l}\text { FA } \\
\text { FR }\end{array}$ & $\begin{array}{c}36 \\
100,0 \% \\
\end{array}$ & $\begin{array}{c}26 \\
100,0 \% \\
\end{array}$ & $\begin{array}{c}9 \\
100,0 \%\end{array}$ & $\begin{array}{c}71 \\
100,0 \% \\
\end{array}$ \\
\hline
\end{tabular}

a. Qui-quadrado $=18,5 ; p=0,005$

Tabela 6. Frequência absoluta (FA), frequência relativa (FR) e resultado do teste de Qui-quadrado para a variável "opinião dos professores/treinadores quanto às condições de uso dos materiais"

\begin{tabular}{|c|c|c|c|c|c|}
\hline & & \multicolumn{3}{|c|}{ ORIGEM DAS ESCOLAS $^{a}$} & \multirow[b]{2}{*}{ Total } \\
\hline & & PRIVADAS & MUNICIPAIS & ESTADUAIS & \\
\hline Precário & $\begin{array}{l}\text { FA } \\
\text { FR }\end{array}$ & $\begin{array}{c}1 \\
2,0 \%\end{array}$ & $\begin{array}{c}14 \\
53,8 \%\end{array}$ & $\begin{array}{c}3 \\
30,0 \%\end{array}$ & $\begin{array}{c}18 \\
21,2 \%\end{array}$ \\
\hline Satisfatório & $\begin{array}{l}\text { FA } \\
\text { FR }\end{array}$ & $\begin{array}{c}14 \\
28,6 \% \\
\end{array}$ & $\begin{array}{c}10 \\
38,5 \% \\
\end{array}$ & $\begin{array}{c}1 \\
10,0 \% \\
\end{array}$ & $\begin{array}{c}25 \\
29,4 \% \\
\end{array}$ \\
\hline Bom & $\begin{array}{l}\mathrm{FA} \\
\mathrm{FR}\end{array}$ & $\begin{array}{c}22 \\
44,9 \% \\
\end{array}$ & $\begin{array}{c}2 \\
7,7 \% \\
\end{array}$ & $\begin{array}{c}2 \\
20,0 \% \\
\end{array}$ & $\begin{array}{c}26 \\
30,6 \% \\
\end{array}$ \\
\hline Ótimo & $\begin{array}{l}\text { FA } \\
\text { FR }\end{array}$ & $\begin{array}{c}12 \\
24,5 \% \\
\end{array}$ & $\begin{array}{c}0 \\
0 \%\end{array}$ & $\begin{array}{c}4 \\
40,0 \% \\
\end{array}$ & $\begin{array}{c}16 \\
18,8 \% \\
\end{array}$ \\
\hline Total & $\begin{array}{l}\mathrm{FA} \\
\mathrm{FR}\end{array}$ & $\begin{array}{c}49 \\
100,0 \%\end{array}$ & $\begin{array}{c}26 \\
100,0 \% \\
\end{array}$ & $\begin{array}{c}10 \\
100,0 \% \\
\end{array}$ & $\begin{array}{c}85 \\
100,0 \%\end{array}$ \\
\hline
\end{tabular}

a. Qui-quadrado $=40,1 ; p=0,000$ 
Em geral, os professores/treinadores consideram as instalações satisfatórias ou boas. No entanto, $26,9 \%$ e $22,2 \%$ das escolas municipais e estaduais, respectivamente, foram classificadas como instituições com instalações precárias (Tabela 5). Para boa parte dos professores/treinadores das escolas privadas e estaduais, as condições de uso dos materiais são boas e ótimas; o mesmo não é verificado nas escolas municipais, onde para a maioria dos professores as condições são precárias (Tabela $6)$.

Os professores/treinadores das escolas públicas relataram piores condições de uso e manutenção das instalações e materiais. Estas evidências concordam com pesquisa realizada com professores de escolas do Estado de São Paulo, em que $42 \%$ dos professores relataram que utilizavam o pátio da escola, pois não dispunham de quadra, e $81 \%$ deles consideravam os materiais insuficientes (TOKUYOCHI et al., 2008).

As escolas municipais avaliadas possuem muitas instalações, pois o programa "Escola Total" é fruto da parceria entre a Secretaria de Esportes e a comunidade. Nessas escolas municipais, o modelo é o de escola em tempo integral que, de acordo com Cavaliere (2009), tende a articular instituições e projetos da sociedade, não necessariamente no espaço escolar, mas, preferencialmente, fora dele. A autora cita que outra forma de oferecer o tempo integral é investir em mudanças no interior das unidades escolares, de forma que possam oferecer condições compatíveis com a presença de alunos e professores em turno integral. Três escolas municipais foram recentemente construídas para atender ao contra turno dentro da própria escola.

No programa Segundo Tempo (utilizado nas escolas municipais), afirma-se que poderão ser utilizados os espaços físicos escolares ou comunitários, públicos ou privados, preferencialmente localizados próximos à comunidade beneficiada, que não demandem transporte para o deslocamento dos beneficiados (BRASIL, 2009). No caso do município de Santos, um vínculo com a Prefeitura permite 0 deslocamento de ônibus, pois não é sempre as instalações estão próximas às escolas.

Os materiais utilizados nas escolas do Município são enviados através do programa
"Segundo Tempo", os quais são confeccionados por participantes do programa "Pintando a Liberdade", que consiste numa proposta do Ministério do Esporte de capacitar pessoas em situação de risco social para trabalharem em fábricas de material esportivo. O programa objetiva a inclusão social de comunidades carentes, facilitando seu ingresso no mercado de trabalho (BRASIL, 2009). E, são distribuídas, por ano, e para cada 100 crianças: cinco bolas (por modalidade), uma rede (por modalidade), 120 camisetas, além de 1.000 reais para a aquisição de material suplementar. Nota-se que a qualidade dos materiais enviados pelo "Segundo Tempo" foi considerada precária pelos professores/treinadores avaliados.

Os professores/treinadores de escolas privadas consideraram os materiais bons $e$ ótimos, concordando com Letnnin (2005), que encontrou resultados semelhantes (estado entre bom e ótimo) em trabalho realizado com escolas privadas.

A intersetorialidade e participação da comunidade podem ser as opções para a melhoria da qualidade dos materiais nas PEEs do setor público (PACHECO, 2009). Conforme descrito na política setorial de esporte (BRASIL, 2005), cabe ao Ministério do Esporte uma articulação e uma maior interlocução com o Ministério da Educação e as Secretarias Estaduais e Municipais de Educação e de Esporte e Lazer, para fortalecer e requalificar o espaço da Educação Física, que garanta garantindo a existência de instalações e materiais esportivos de qualidade, e propicie o acesso de todos os escolares à prática esportiva.

\section{Conclusão}

As diferenças observadas entre os professores da rede privada, municipal e estadual em relação à idade, experiência, formação e atualização, podem ter origem na própria natureza dos programas aos quais pertencem. Chama-nos atenção a idade e a experiência inferior em relação aos professores de diferentes disciplinas no ensino fundamental e na Educação Física Escolar, o que pode revelar a inexperiência dos professores/treinadores de PEEs, sobretudo de escolas municipais e privadas. Considerando a experiência como importante fator de sucesso no ensino-aprendizagem, sugere-se que os programas criem estratégias para manter os professores/treinadores nas PEEs, seja 
contratando alguns dos estagiários, no caso do programa do município, ou criando melhores vínculos trabalhistas como no caso das escolas privadas.

O maior percentual de professores/treinadores ex-atletas nas escolas privadas pode ser explicado pelo envolvimento destas em torneios competitivos. No entanto, isso pode vir a ser um problema na medida em que os gestores que acreditam que os professores/treinadores que foram atletas medalhistas poderiam formar atletas campeões. A experiência como atleta é considerada uma forma de aquisição de conhecimento, contudo, considerá-la suficiente pode resultar em professores/treinadores que reproduzem condutas, comportamentos e métodos de treinamento de sua experiência anterior, não importando se a mesma é questionável ou não encontre apoio científico.

Apesar dos professores/treinadores das escolas privadas e estaduais participarem de cursos de atualização, estes não realizam reuniões na escola em que trabalham. Sugere-se que as escolas ou órgãos gestores ofereçam programas de formação continuada aos professores/treinadores, de forma que possam discutir sua ação docente e os instrumentos teórico-metodológicos por meio de uma prática reflexiva. No âmbito público (sobretudo no Estado de São Paulo), ao invés da prioridade ser a realização de torneios (eventos esportivos), poder-se-ia pensar em encontros (workshops), elaboração de material de apoio, reuniões pedagógicas, entre outras estratégias.

Os professores/treinadores das escolas públicas relataram piores condições de uso e manutenção das instalações e materiais. As escolas municipais avaliadas possuem muitas instalações, pois o programa "Escola Total" é fruto de parceria com a Secretaria de Esportes e a comunidade. Nessas escolas municipais, 0 modelo é o da escola em tempo integral, que tende a articular instituições e projetos da sociedade, não necessariamente no espaço escolar, mas, preferencialmente, fora dele. Nesse sentido, uma possibilidade no setor público seria restaurar e reaproveitar esses espaços cedidos pela comunidade. Além disso, em cidades litorâneas, a utilização da praia poderia ser uma possibilidade de oferecimento das PEEs.

A intersetorialidade e a participação da comunidade podem ser as opções para a melhoria da qualidade dos materiais nas PEEs do setor público. É papel do Ministério do Esporte articular e intermediar o diálogo e o encontro entre - Ministério da Educação e as Secretarias Estaduais e Municipais de Educação e de Esporte e Lazer, a fim de fortalecer e requalificar o espaço da Educação Física, garantir instalações e materiais esportivos de qualidade, e propiciar o acesso de todos os escolares à prática esportiva.

A partir do exposto, esperamos que os dados ora levantados, estimulem e subsidiem futuras discussões sobre programas de iniciação esportiva no contexto escolar.

\section{Referências}

ARENA, S. S. Iniciação e especialização esportiva na grande São Paulo. 2000. $105 f$. Dissertação (Mestrado) - Escola de Educação Física e Esporte da Universidade de São Paulo, São Paulo.

BASSANI, J. J.; TORRI, D.; VAZ, A.F. Sobre a presença do esporte na escola: paradoxos e ambigüidades. Revista Movimento, Porto Alegre, v. 9, n. 2, p. 89-112, 2003. Disponível em: http://seer.ufrgs.br/Movimento/article/view/2811/14 26. Acesso em: 10 nov. 2010.

BRASIL. Ministério da Educação e do Desporto. Lei $\mathrm{n}^{\circ}$ 9.394, de 20 de dezembro de 1996: estabelece as diretrizes e bases da educação nacional. Brasília, 1996. Disponível em: http://www.planalto.gov.br/ccivil 03/Leis/L9394.ht m. Acesso em: 18 nov. 2009.

BRASIL. Ministério do Esporte. Política Nacional de Esporte. Brasília, 2005. Disponível em: http://portal.esporte.gov.br/arquivos/politicaNacion al/politicaNacionalCompleto.pdf. Acesso em: Acesso em: 18 nov. 2009.

BRASIL. Ministério do Esporte. Secretaria Nacional de Esporte Educacional. Diretrizes e Orientações para Estabelecimento de Parcerias do Segundo Tempo. Disponível em: http://portal.esporte.gov.br/snee/segundotempo/de fault.jsp. Acesso em: 18 nov. 2009.

CAVALIERE, A. M. Escolas de tempo integral versus alunos em tempo integral. Em Aberto, Brasília, v. 22, n. 80, p. 51-63, 2009.

GADOTTI. M. Perspectivas atuais da educação. Porto Alegre: Artes Médicas, 2000.

\section{LETTNIN, C. C. Esporte escolar: razão e}

finalidades. 2005. 154p. Dissertação (Mestrado) apresentada ao Programa de Mestrado em Educação Física da Universidade Federal de 
Santa Catarina, Santa Catarina, 2005. Disponível em:

http://www.diaadiaeducacao.pr.gov.br/diaadia/diad ia/arquivos/File/conteudo/artigos teses/EDUCAC AO FISICA/dissertacao/esporte.escolar.pdf. Acesso em: 10 nov. 2010.

\section{LIBÂNEO, J. C. Organização e gestão da} escola: teoria e prática. Goiânia: Alternativa, 2004.

LUGUETTI, C. N. Práticas esportivas escolares no ensino fundamental no município de Santos-SP. 2010. 149f. Dissertação (Mestrado) Escola de Educação Física e Esporte da Universidade de São Paulo, São Paulo. Disponível em:

http://www.teses.usp.br/teses/disponiveis/39/3913 4/tde-18082010-172722/pt-br.php. Acesso em: 10 nov. 2010.

MARCON, D.; GRAÇA, A. B. S.; NASCIMENTO, J.V. Estruturantes da base de conhecimentos para o ensino de estudantes-professores de Educação Física. Motriz, Rio Claro, v.16 n.3 p.776-787, 2010. Disponível em:

http://www.periodicos.rc.biblioteca.unesp.br/index. php/motriz/article/viewFile/3475/3216. Acesso em: 10 nov. 2010.

MOLINA, R. K.; MOLINA NETO, V. O pensamento dos professores de educação física sobre a formação permanente no contexto da escola cidadã: um estudo preliminar. Revista Brasileira de Ciência do Esporte, Florianópolis, v. 22, n. 3, p. 73-85, 2001. Disponível em: http://www.rbceonline.org.br/revista/index.php?jou rnal=RBCE\&page $=$ article\&op=view\&path\%5B\%5D $=384 \&$ path $\% 5 \mathrm{~B} \% 5 \mathrm{D}=328$. Acesso em: 10 nov. 2010.

NELSON, L. J.; CUSHION, C. J.; POTRAC, P. Formal, Nonformal and Informal Coach Learning: A Holistic Conceptualisation. International Journal of Sport Science \& Coaching, United Kingdom, v.1, n.3, p.247-259, 2006.

NUNOMURA, M.; CARRARA, P. D. S.; CARBINATTO, M. Ginástica artística competitiva: considerações sobre o desenvolvimento dos ginastas. Motriz, Rio Claro, v.15 n.3 p.503-514, 2009. Disponível em:

http://www.periodicos.rc.biblioteca.unesp.br/index. php/motriz/article/view/2222/2427. Acesso em: 10 nov. 2010.

PACHECO, R. T. B. O espetáculo da educação: os Centros Educacionais Unificados do Município de São Paulo como espaços públicos de lazer. 2009. 280f. Tese (Doutorado em Educação na área de Concentração Estado, Sociedade e Educação). Faculdade de Educação da Universidade de São Paulo. Disponível em: http://www.teses.usp.br/teses/disponiveis/48/4813 4/tde-09092009-163829/pt-br.php. Acesso em: 10 nov. 2010.

SAFRIT, M. Evaluation in Physical Educations. New Jersey: Prentice Hall, 1981.

SANTOS, A. L.; SIMÕES, A.C. A influência da participação de alunos em práticas esportivas escolares na percepção do clima ambiental da escola. Revista Portuguesa de Ciência do Desporto, Porto, v. 7, n.1, p. 26-35, 2007. Disponível em: http://www.scielo.oces.mctes.pt/pdf/rpcd/v7n1/v7n 1a04.pdf.

SARTORI, R. F. Projeto esporte escolar e o impacto no desenvolvimento de seus participantes em uma comunidade de São José (SC). Revista Brasileira de Cineantropometria e Desempenho Humano, Santa Catarina, v. 7, n.1, 2005. Disponível em: http://www.rbcdh.ufsc.br/DownloadArtigo.do?artig o=193. Acesso em: 29 nov. 2010.

SIGOLI, M. A. O esporte educacional e a prática esportiva nas escolas da cidade de São Paulo. 2005. 62f. Dissertação (Mestrado) Escola de Educação Física e Esporte da Universidade de São Paulo, São Paulo.

SOARES, L. M. A. Esporte escolar: concepções e práticas. 2003. 133f. Dissertação (Mestrado) Escola de Educação Física e Esporte da Universidade de São Paulo, São Paulo, 2003.

THOMAS, J.; NELSON, J. Métodos de pesquisa em atividade física. Porto Alegre: Artmed, 2002.

TOKUYOCHI, J. H.; BIGOTTI, S.; ANTUNES, F.; CERENCIO, M. M.; DANTAS, L.E.P.B.T.; MARCOS, H.L.; SOUZA, E.; TANI, G . Retrato dos professores de Educação Física das escolas estaduais do estado de São Paulo. Motriz, Rio Claro, v. 14, p. 418-428, 2008. Disponível em: http://www.periodicos.rc.biblioteca.unesp.br/index. php/motriz/article/viewArticle/1361. Acesso em: 29 nov. 2010.

TRUDEL, P.; GILBERT, W. Coaching and Coach Education. In: KIRK, D.; MACDONALD, D.; O SULLIVAN, M. The Handbook of Physical Education. London: Sage Publications, 2006. p. 531-554.

TSUKAMOTO, M.H.C. A ginástica olímpica no contexto da iniciação esportiva. 2004. $156 \mathrm{f}$. Dissertação (Mestrado) - Escola de Educação Física e Esporte, Universidade de São Paulo, São Paulo.

UNESCO, Pesquisa Nacional. O perfil dos professores Brasileiros: o que fazem, o que 
pensam, o que almejam. São Paulo: Moderna, 2004. Disponível em:

http://www.dominiopublico.gov.br/download/texto/ ue000027.pdf. Acesso em: 29 nov. 2010.

\section{Endereço:}

Carla Nascimento Luguetti

Av. Bartolomeu de Gusmão, 37/146c - Boqueirão Santos SP Brasil

$11045-400$

Telefone: (13) 9182.8932

e-mail: luguetti@usp.br

Recebido em: 7 de dezembro de 2010.

Aceito em: 18 de novembro de 2012.

\section{(c) (7)}

Motriz. Revista de Educação Física. UNESP, Rio Claro, SP, Brasil - elSSN: 1980-6574 - está licenciada sob Creative Commons - Atribuicão 3.0 